\title{
Implementation of Roll On - Roll off system for transporting bottled lpg to the interior of Amazonas state.
}

\author{
Marcelo da Silva Andion ${ }^{1}$; Izabel Pinheiro Andion² \\ ${ }^{1,2}$ Universidade Paulista (UNIP). Av Mário Ypiranga, 4390, Parque 10 de novembro - Manaus-AM- Brasil. \\ (marceloandion1@gmail.com, ipandion@gmail.com)
}

\begin{abstract}
Fluvial transport of LPG into the state of Amazonas (Brazil) has been made precarious and artisanal over the years. The solution to this problem was the implementation of the system roll on - roll off to boarding canisters of LPG that are sent to the state. This paper presents the case study and the solution to the faced problem. The specific objectives, as well as the results from the implementation of this new mode of delivery of LPG cylinders for the interior of the Amazonas state, will be presented in this article.
\end{abstract}

Keywords: Planning. Customers. Logistics. Workplace safety

\section{Implantação de Sistema Roll On - Roll off Para o transporte de glp envasado para o interior do estado do Amazonas}

\begin{abstract}
RESUMO
O transporte Fluvial de GLP para o interior do Estado do Amazonas (Brasil) vem sendo feito de forma precária e artesanal ao longo dos anos. A solução para este problema foi a implantação do sistema roll on - roll off para o embarque de botijões de GLP que são enviados ao interior do estado. Este trabalho, apresenta o estudo de caso e a solução do problema apresentado. Os objetivos específicos, assim como os resultados encontrados com a implantação deste novo modal de envio de botijões de GLP para o Interior do estado, serão apresentados ao longo deste artigo.
\end{abstract}

Palavras Chaves: Planejamento. Clientes. Logística. Segurança do Trabalho.

\section{INTRODUÇÃO}

A utilização do planejamento estratégico em uma organização é um processo que, quando bem implementado, mobiliza as empresas e seus colaboradores em busca de resultados de longo prazo. O Planejamento Estratégico através da metodologia Balanced Scorecard, possui quatro pilares fundamentais que são: pessoas, processos internos, clientes e finanças. Basicamente pessoas bem treinadas, qualificadas, motivadas, executam processos internos de forma eficiente, fazendo com que os clientes fiquem satisfeitos $\mathrm{e}$ consequentemente, a empresa tenha rentabilidade superior. Todos os colaboradores da organização precisam estar focados no planejamento e execução da estratégia da organização.

O pilar processos internos, precisa estar em constante evolução, com inovações que tragam agilidade aos processos executados, tendo em vista que os clientes estão cada vez mais exigentes. O sistema de gestão, com a utilização de indicadores que apontem as oportunidades de melhoria, completa as etapas do planejamento organizacional.
O processo de entregas para os Revendedores dos municípios que são acessados somente por via Fluvial no Amazonas, historicamente, sempre foi de elevado grau de complexidade. A análise dos indicadores relativo aos processos desta atividade, apontavam para um elevado índice de insatisfação por parte da rede de Revendedores, devido a demora para conclusão do desembarque de botijões vazios e embarque de botijões cheios, assim como custos elevados e riscos de acidentes, ergonômicos e físicos.

O presente artigo trata da implantação do sistema roll on - roll off para o transporte de botijões de GLP para os municípios do estado do Amazonas que são acessados somente pelo modal de Transporte Fluvial.

O transporte de botijões para estes municípios é realizado em balsas de diferentes portes, conforme demonstrado na figura. 


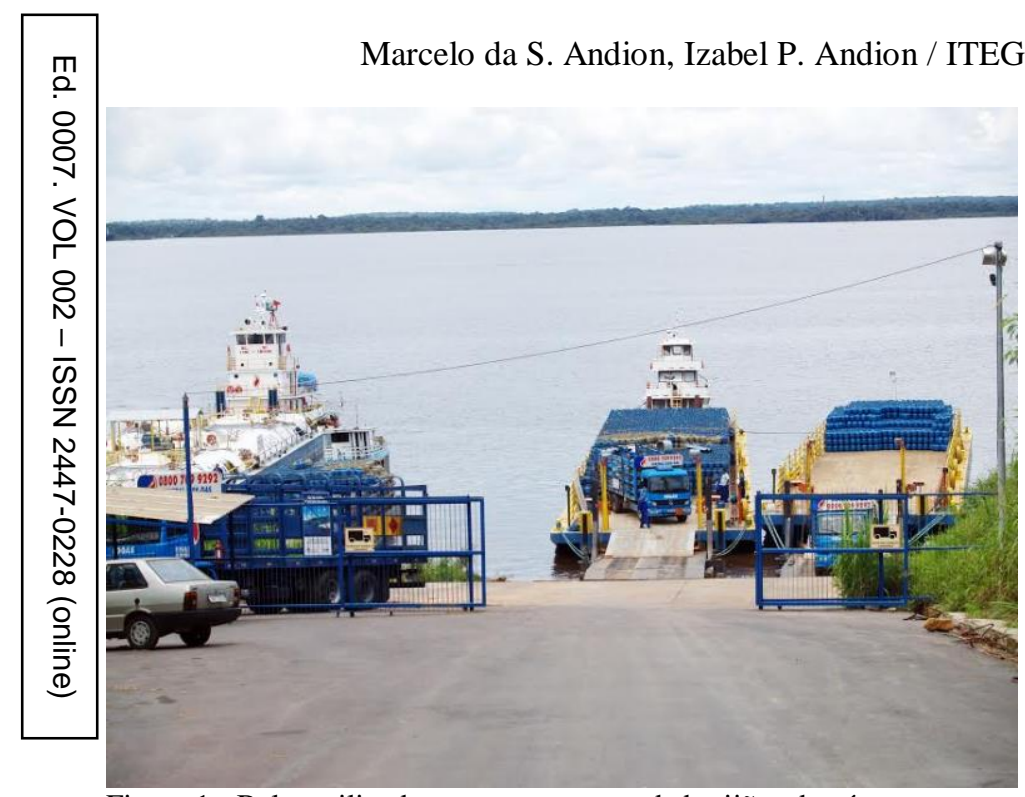

Figura 1 - Balsa utilizada para o transporte de botijões de gás

A complexidade na execução das tarefas realizadas para o embarque e desembarque de botijões para o interior Fluvial tem suas etapas simplificadas, previstas na figura 2.

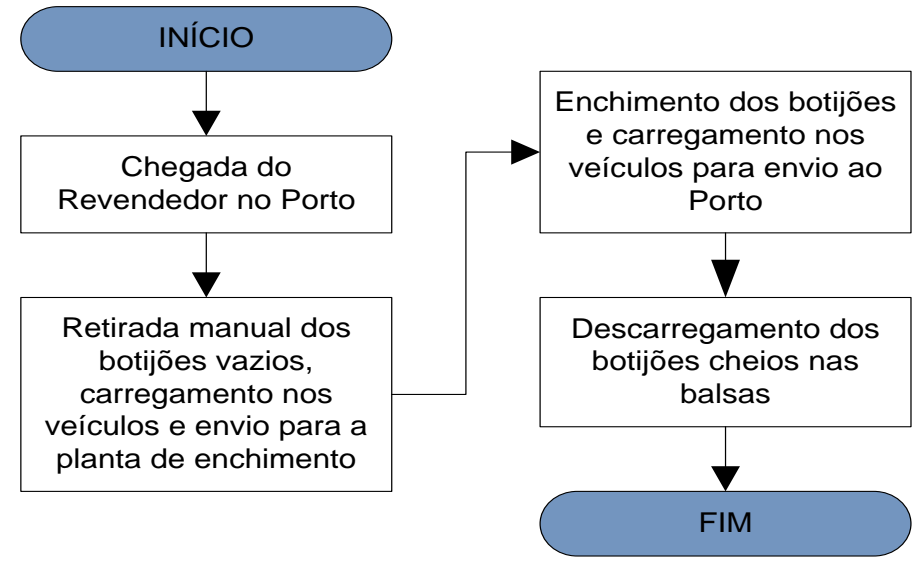

Figura 2 - Fluxograma simplificado do Processo de Embarque e Desembarque de botijões de Gás para o interior Fluvial do Amazonas.

Fonte: Os autores, (2016).

Com a implantação do sistema rol on-roll off para o abastecimento das Revendas destes municípios, os objetivos principais foram:

Reduzir o tempo de espera das Revendas em Manaus, proporcionando o aumento da satisfação destes clientes;

Reduzir a mão de obra utilizada no manuseio do desembarque e embarque de vasilhames, reduzindo assim os riscos de acidentes, ergonômicos e físicos;

Reduzir o custo com mão de obra envolvida neste processo.

\section{REVISÃO BIBLIOGRÁFICA}

A distribuição de botijões de gás de cozinha no interior do Estado do Amazonas é realizada através de Revendedores autorizados pela Agência Nacional do Petróleo. Estes Revendedores realizam a retirada dos botijões de gás em Manaus e fazem o transporte em balsas para as cidades onde atuam.

As frequentes mudanças no cenário econômico nacional, obrigam as organizações a buscarem reformulações em seu processo de gestão, buscando soluções que contribuam para elevar a rentabilidade, flexibilidade e eficiência dos seus processos produtivos e administrativos, incluindo aí os processos de logística de entregas e distribuição[1].

Quando foi implantado, o Balanced Scorecard (BSC) era visto como um sistema de avaliação de desempenho através de indicadores de dimensões financeiras e não-financeira. Atualmente o BSC é conhecido como sendo um sistema de gestão estratégica que proporciona uma visão geral da organização, proporcionando a visualização de oportunidades de melhorias que podem levar a organização a gozar de vida longa [2].

Segundo Kaplan [3], o painel de desempenho é uma forma que as organizações utilizam para: descrever a visão e a estratégia da organização, comunicar os objetivos e os indicadores estratégicos, alinhar as estratégias organizações e implantar a estratégia.

Para os criadores desta ferramenta, o BSC pode ser utilizado de forma abrangente pelas organizações para viabilizar processos críticos como:

1) esclarecer e traduzir a visão e a estratégia;

2) comunicar e associar objetivos e medidas estratégicas;

3) planejar, estabelecer metas e alinhar iniciativas estratégicas;

4) Melhorar o feedback e o aprendizado estratégico[3].

O Balanced Scorecard (BSC) se propõe a medir o desempenho das empresas através de quatro dimensões, quais sejam: pessoas (aprendizagem), processos de negócios (processos internos), clientes e finanças [4].

A perspectiva dos processos internos, objeto de estudo deste artigo, deve, necessariamente, ser direcionada para os processos que possuem impacto direto na satisfação do cliente, que consequentemente trará resultado para os objetivos financeiros da empresa.

O objetivo principal deste projeto foi desenvolver uma forma de melhorar o Lead Time do processo de embarque e desembarque de botijões para o interior fluvial do AM, através do desenvolvimento de tecnologia necessária para a implantação do sistema de roll on- roll off [5], com a utilização de carretas.

\section{MATERIAIS E MÉTODOS}

Após identificação do problema com o Lead Time das entregas, foram realizadas reuniões com o objetivo de identificar as causas que estavam levando a demora nas entregas. Como 
Marcelo da S. Andion, Izabel P. Andion / ITEGAM-JETIA Vol.02, Nº 07, pp.37-41. Setembro, 2016.

resultado destas reuniões, foram gerados o Diagrama de Causa e Efeito apresentado de forma resumida na figura 3.

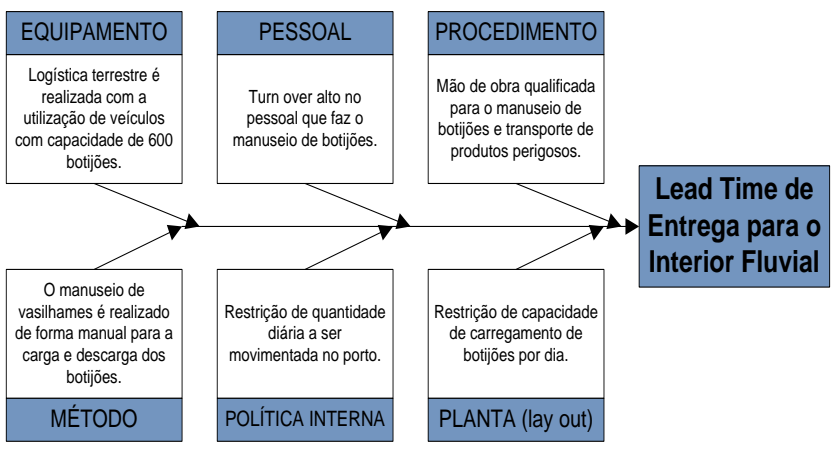

Figura 3 - Diagrama de Causa e Efeito.

Fonte: Os autores, (2016).

Analisadas as causas, foi então elaborado o plano de ação para solução em definitivo do problema, que seria a implantação do sistema de roll on-roll off, ou seja, o Revendedor passaria a levar para o interior os botijões cheios em carretas, com capacidade aproximada de 1.300 botijões, que já sairia carregada da Fogás e seria embarcada direto na balsa do Revendedor.

O plano de ação foi implantado de forma gradual, pois envolveu ações de longo prazo, que precisaram ser implantadas junto a fornecedores e clientes. O processo de implantação deste novo modal de entregas, levou aproximadamente dois anos.

As ações macro realizadas foram:

$\checkmark$ Adequação das embarcações dos Revendedores para o transporte de carretas, em quantidades adequadas às suas necessidades;

$\checkmark$ Aquisição de carretas para o armazenamento de botijões cheios e utilização pelos Revendedores;

$\checkmark$ Contratação de porto específico para o embarque e desembarque de carretas;

Elaboração de contrato específico para o comodato das carretas aos Revendedores;

$\checkmark$ Manter estoque mínimo de 20 carretas carregadas com botijões cheios, de forma a otimizar o tempo de descarga e carga das balsas dos Revendedores;

$\checkmark$ Realocar cavalo mecânico para o transporte das carretas da Empresa, para o porto contratado;

Desenvolvimento de um projeto padronizado de carretas que possibilitasse a abertura na parte frontal e lateral das carretas, com as portas sendo erguidas para cima, facilitando o manuseio dos botijões e ainda possibilitando a redução de espaço entre uma carreta e outra.
Após a implantação de todas as ações apontadas, iniciouse a migração de forma gradativa do novo modal.

\section{RESULTADOS E DISCUSSÕES}

A realização de investimentos em infraestrutura terrestre e portuária no interior do Amazonas é ponto de vital importância para garantir o abastecimento da região [6]. Estes investimentos, em sua maioria, precisam ser feitos pelo setor privado, focando na redução dos custos e na agilidade do tráfego de produtos essenciais para a região [7]. Neste aspecto, a logística é fundamental para buscar alternativas [8] que permitam a redução de custos e o aumento da produtividade, passando então, a logística, a ser fator primordial para a solução dos problemas estruturais da região.

Analisando a rede de distribuição de Revendedores do interior do Estado do Amazonas, para os Revendedores que atuam na cidade de Manaus, capital do Estado, observou-se uma grande diferença entre os mesmos, principalmente pelo fato de os Revendedores de Manaus receberem diretamente em suas Revendas, pequenas quantidades do produto, com entregas realizadas pela Distribuidora, em intervalo médio de dois dias entre uma entrega e outra. Já no interior do Estado, os Revendedores precisam se deslocar de seus municípios até Manaus, para retirar o produto na Distribuidora, sendo os responsáveis pelo custo deste transporte nos grandes rios, assim como pelo manuseio dos botijões de gás nas balsas.

O Amazonas é o maior estado do país, possuindo uma área de $1.571 .000 \mathrm{Km}^{2}$ [9], que estão distribuídos em 62 municípios. O transporte fluvial é responsável pelo abastecimento de maior parte destes municípios, sendo, em alguns casos, a única opção disponível. Estes municípios têm em comum o fato de se distanciarem da capital e ainda de registrarem grandes distâncias entre eles. Estas distâncias, dependendo da sazonalidade dos rios, podem ser alteradas, já que em épocas de cheias e vazantes, as distâncias podem ser encurtadas ou ampliadas.

Segundo [10] a prestação de serviços na área de logística compreende o gerenciamento estratégico das aquisições, transporte e armazenamento de matérias primas e de produtos acabados, focando na lucratividade atual e futura.

Com base nas informações estratégicas geradas pelos indicadores relativos aos processos internos, focou-se na melhoria do processo de logística (embarque e desembarque) de botijões para o interior do Amazonas.

Os Revendedores que fazem o transporte para o interior do estado foram contatados pela organização, com relação à disponibilidade de adequação de suas embarcações, para o transporte de carretas. Entre os dezoito Revendedores contatados, somente cinco (28\%) alegaram não estar dispostos em investir na adequação das embarcações, mesmo tendo a garantia de que o tempo de embarque/desembarque seria reduzido, possibilitando a realização de um número maior de viagens por parte do Revendedor. 
Realizada esta etapa inicial de contato com as Revendas, a empresa decidiu dar andamento no projeto piloto, iniciando o processo de aquisição de carretas para fazerem o armazenamento e posterior entrega do produto nos portos.

Inicialmente foram adquiridas carretas com modelos já disponíveis no mercado, conforme demonstrado na figura 4.

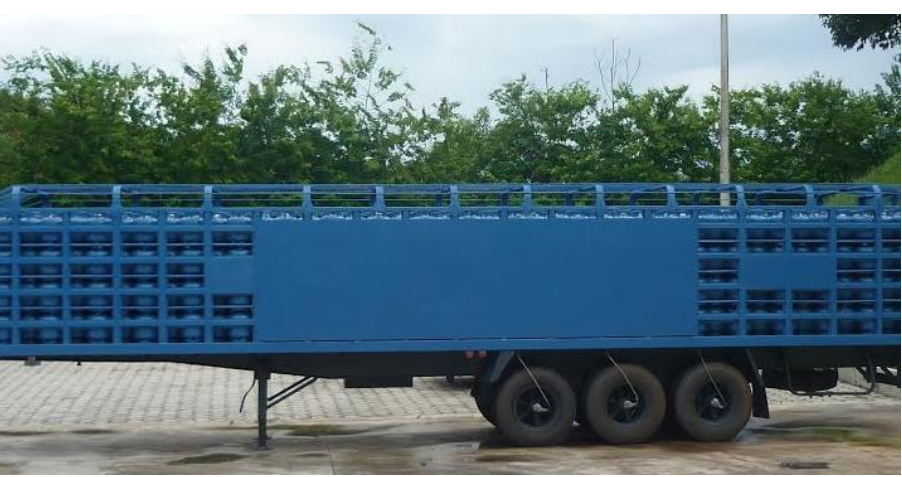

Figura 4 - Carretas utilizadas no início do projeto roll on - roll off.

Fonte: Os autores, (2016).

No entanto, as carretas já disponíveis se apresentaram ineficientes no processo, pois dificultavam o manuseio dos vasilhames dentro das mesmas, já que o único acesso a elas era pela parte traseira das mesmas.

Desta forma, a organização definiu pela confecção de projeto padronizado, que atendesse a demanda dos Revendedores em facilitar o processo de manuseio, buscando parceria para confecção de carretas padronizadas, conforme demonstrado na figura 5. Este fator foi primordial para o sucesso deste novo modal. Carretas padronizadas, que permitem o manuseio de vasilhames pela parte dianteira, traseira e ainda pelas laterais.
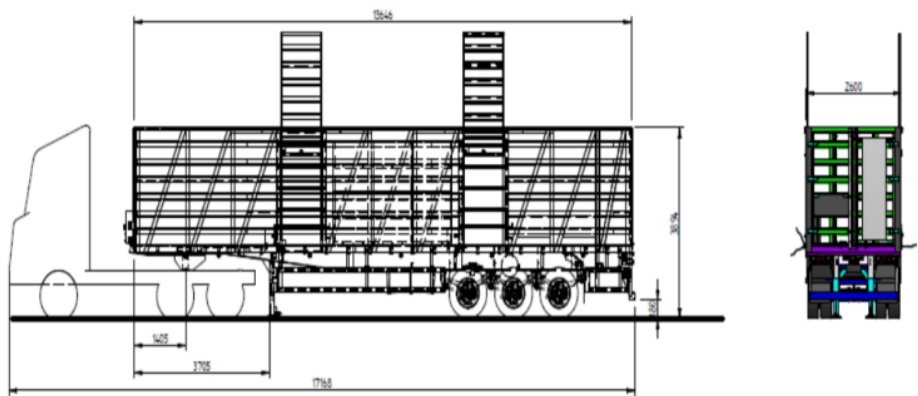

Figura 5 - Projeto de carreta desenvolvido para atender às necessidades dos Revendedores.

Fonte: Os autores, (2016).

Realizada a aquisição das carretas, a organização passou a utilizá-las como "estoque de produto acabado", mantendo um estoque mínimo de vinte carretas carregadas no pátio, reduzindo mais ainda o tempo médio de espera dos Revendedores no porto.

Os resultados encontrados, permitem assegurar que o projeto está sendo bem-sucedido, alcançando os objetivos esperados pela organização.
O custo com a mão de obra de colaboradores envolvidos no processo de manuseio de botijões em cima da balsa, assim como dos motoristas responsáveis pelo transporte dos veículos até o porto, reduziu em $94 \%$ (noventa e quatro pontos percentuais).

Com a eliminação da movimentação de vasilhames em cima das balsas, a taxa de gravidade de acidentes está com nível zero de dezembro/2015 a junho/2016, conforme pode ser observado na figura 6 .

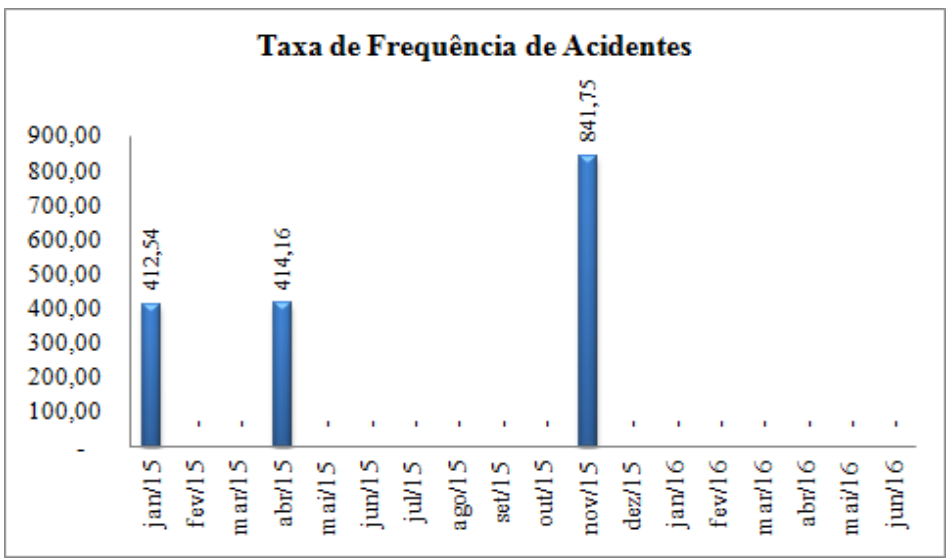

Figura 6 - Taxa de Frequência de acidentes com o manuseio de botijões em cima de balsas.

Fonte: Os autores, (2016).

O tempo de embarque/desembarque reduziu significativamente, passando a ser um dos pontos mais elogiados pelos Revendedores. Revendedores que no modal anterior passavam 10 dias para embarcar/desembarcar em torno de 26.000 botijões, passaram a fazer esta mesma quantidade em qutro horas de trabalho aproximadamente, fazendo que pudessem investir o tempo em outras atividades e passando a fazer, em alguns casos, até 2 viagens por mês.

\begin{tabular}{|l|r|l|}
\hline \multicolumn{3}{|c|}{ LEAD TIME DE ENTREGAS } \\
\hline Veiculos Utilizados & 6,0 & caminhões \\
Capacidade & 600,0 & botijões \\
Logistica Terrestre (ida/volta) & 86,7 & viagens \\
Tempo de Carga/Descarga na balsa & 10,4 & dias \\
Mão de Obra utilizada & 18,0 & Colaboradores \\
\hline
\end{tabular}

\begin{tabular}{|l|r|l|}
\hline \multicolumn{3}{|c|}{ DEPOIS } \\
\hline Carretas utilizadas & 20,0 & carretas \\
Capacidade de cada carretas & $1.300,0$ & botijões \\
Logistica Terrestre (ida/volta) & 40,0 & viagens \\
Tempo de Carga/Descarga na balsa & 4,0 & horas \\
Mão de Obra & 1,0 & Colaborador \\
\hline
\end{tabular}

Figura 7 - Lead Time de Embarque/Desembarque de botijões para o Interior Fluvial.

Fonte: Os autores, (2016). 
Os cinco revendedores, que no início do projeto afirmaram não estar dispostos a investir na adequação de suas embarcações para o transporte de carretas, se adequaram e passaram a fazer o transporte desta forma, principalmente devido a redução do tempo parado para o embarque/desembarque da embarcação.

A organização tem mantido estoque de carretas carregadas com botijões cheios, conforme figura 8 , o que facilita o embarque, fazendo com que o lead time se mantenha reduzido para o processo de embarque.

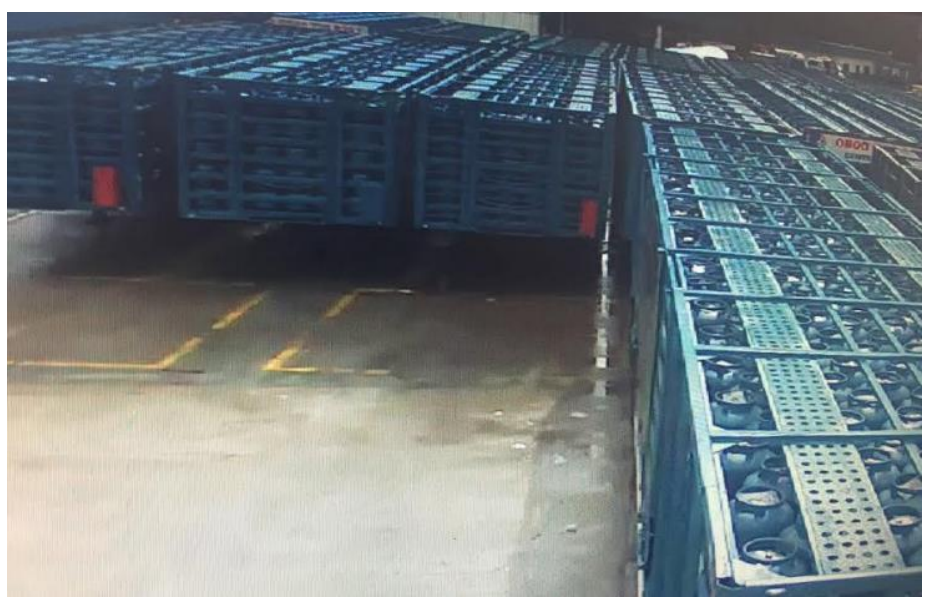

Figura 8 - Estoque de carretas carregadas com botijões cheios.

Fonte: Os autores, (2016).

\section{CONCLUSÃO}

A logística de distribuição é de extrema importância para estimular as atividades comerciais de uma empresa. Na região amazônica, por ser uma região de difícil acesso, surgem novos desafios a cada dia, principalmente no que se refere a sazonalidade dos rios, navegabilidade, características físicas e geográficas e, principalmente, à falta de estrutura dos portos da região, fazendo com a logística nesta região seja um desafio de extrema complexidade.

A implantação do sistema roll on-roll off colocou em evidência a responsabilidade da empresa em atender bem aos seus clientes, assim como o seu compromisso com o abastecimento de todas as cidades em que atua.

A análise dos dados de antes e depois da implantação do sistema de entregas para o interior Fluvial através do modal roll on -roll off, comprova que o novo sistema produziu o efeito esperado na organização. As reclamações de Revendedores que são atendidos por este modal reduziram a nível zero, representando o aumento da satisfação destes clientes.

O tempo de espera para carregamento de uma balsa com vinte e seis mil botijões, que antes da implantação deste modal, dependendo da fila de espera, era em torno de dez dias, reduziu para quatro horas.
A redução do manuseio de vasilhames em cima das embarcações dos revendedores, fez com que o número de acidentes com manuseio de vasilhames nas embarcações fosse eliminado.

O custo com mão de obra envolvida neste processo reduziu significativamente, pois não há mais necessidade de pessoal qualificado para o manuseio de vasilhames em cima das embarcações.

\section{AGRADECIMENTOS}

Ao Instituto de Tecnologia e Educação Galileo da Amazônia (ITEGAM) e a Universidade Paulista (UNIP).

\section{REFERÊNCIAS BIBLIOGRÁFICAS}

[1] Keedi, S., Logística de transporte internacional. 2001: Aduaneiras.

[2] Epstein, M. and J.-F. Manzoni, Implementing corporate strategy:: From Tableaux de Bord to balanced scorecards. European Management Journal, 1998. 16(2): p. 190-203.

[3] Kaplan, R.S., Conceptual foundations of the balanced scorecard. Handbooks of management accounting research, 2008. 3: p. $1253-1269$.

[4] Wall, M.E., A. Rechtsteiner, and L.M. Rocha, Singular value decomposition and principal component analysis, in A practical approach to microarray data analysis. 2003, Springer. p. 91-109.

[5] Murgoitio, J., et al., Spanish Initiative for Fully Automated Stowage on Roll-on/roll-off Operations. Transportation Research Procedia, 2016. 14: p. 173-182.

[6] de Souza SOUZA, P.A.R., et al., O serviço de logística de distribuição do interior do Amazonas. REA-Revista Eletrônica de Administração, 2011. 10(2).

[7] Campos Neto, C.A.d.S., et al., Gargalos e demandas da infraestrutura portuária e os investimentos do PAC: mapeamento Ipea de obras portuárias. 2009.

[8] da Silva Filho, L.C. and F.I. da Silva, A LOGÍSTICA NA GESTÃO DE TRANSPORTE. Cadernos UNISUAM de Pesquisa e Extensão, 2016. 5(4): p. 1-9.

[9] Moraes, E.d.O., Espaço e indústria: um estudo sobre a produção e distribuição de motocicletas honda no estado do amazonas. REVISTA IGAPÓ-Revista de Educação Ciência e Tecnologia do IFAM, 2016. 10(1): p. 114-127.

[10] Arbache, F.S., Gestão de logística, distribuição e trade marketing. 2015: Editora FGV. 